\title{
CINEMA, HUMANIZAÇÃO E EDUCAÇÃO EM SAÚDE
}

Pablo González Blasco ${ }^{1}$

\section{Resumo}

O núcleo do processo de Humanização em Saúde consiste em promover a reflexão do profissional, o exercício filosófico da profissão. No contexto desta reflexão humanizante, é preciso considerar o que deve ser humanizado, como fazê-lo, e os custos que a humanização implica. A educação da afetividade e das emoç̃oes é condição necessária para promover atitudes duradouras e eficazes. Assim sendo, o Cinema, que ajuda a refletir sobre aspectos essências da vida, tem se mostrado um recurso metodológico eficaz para promover a reflexão. $\mathrm{O}$ uso do cinema, com destaque para o conjunto de cenas variadas (clips) pode incorporar-se nos projetos pedagógicos de educação em saúde, como é ilustrado neste artigo. A formação humanista do profissional de saúde é potencializada com a metodologia do cinema, buscandose deste modo um modelo de humanismo e humanização sustentável.

Palavras chave: Humanização, Educação em Saúde, Cinema, Educação da Afetividade, Humanismo Médico.

\section{CINEMA, HUMANIZATION AND EDUCATION IN HEALTH}

\begin{abstract}
The core of the process of Humanization in Health consists in promoting the reflection of the professional, which is call the philosophical exercise of the profession. In the context of this humanizing reflection, we must consider what must be humanized, how to do it, and the costs that humanization entails. The education of affectivity and emotions is a necessary condition to promote and incorporate effective attitudes. Cinema, which helps to reflect on essential aspects of life, has proved to be an effective methodological resource to promote reflection. The use of cinema, with emphasis on the set of varied scenes (movie clips) can be incorporated in the pedagogical projects of health education, as is illustrated in this article. The humanist education of the health professional is enhanced by the methodology of the cinema, seeking in this way a model of humanism and sustainable humanization.
\end{abstract}

Keywords: Humanization, Education in Health, Cinema, Education of Affectivity, Medical Humanism.

\section{Motivos de um projeto: educação em saúde com cinema?}

Educar com o Cinema é tema que me tem acompanhado nos últimos anos. Tive ocasião de escrever artigos, publicar livros, dar conferências, incluídos congressos

\footnotetext{
${ }^{1}$ Médico e Doutor em Medicina. Diretor Científico da SOBRAMFA- Educação Médica e Humanismo. www.sobramfa.com.br. E-mail: pablogb@ sobramfa.com.br
} 
internacionais, apresentar-me em programas de TV. Em quase todos os cenários, a pergunta que surge é similar: "Você não é médico? E isto do cinema, como se encaixa na sua vida?". Quando viajo pelo mundo, ocorre o mesmo: Oh, you're the movie guy! A pergunta procede e, até tal ponto, que mesmo quando não a fazem eu mesmo a coloco e respondo. Afinal, é necessário justificar o tempo que se dedica a um trabalho que já ultrapassou de longe as proporções de um simples hobby. "Eu não trabalho em Hollywood. Vejo pacientes todos os dias" -costuma ser meu cartão de visitas nestas circunstancias

Dizer que os profissionais de hoje estão munidos de excelente preparação técnica, não é novidade. Como, infelizmente, também não o é afirmar que carecem, na maioria, da sensibilidade suficiente para lidar com o ser humano doente, que sofre e se confia aos seus cuidados. Fala-se em humanizar a saúde, quando na verdade o que se gostaria é de injetar doses de humanidade nos profissionais para ver se o paciente consegue, de algum modo, se fazer entender por aquele que está destinado a cuidá-lo. O médico, absorvido pela técnica moderna -útil e necessária- parece esquecer o paciente, ocupando-se apenas com a doença. Existe um divórcio entre o médico que se diverte com a técnica, e o paciente que caminha em desamparo com a sua moléstia.

O Cinema tem se mostrado um recurso eficaz para promover a reflexão, para fazer as pessoas pensar (BLASCO et al, 2011). Estudantes e médicos, profissionais da saúde, são convidados através desta metodologia a refletir sobre as suas atitudes. O resultado é que a reflexão surge como o verdadeiro núcleo do processo humanizante (BLASCO et al, 2010). De modo talvez excessivamente simples, pode se dizer que humanizar é, em primeiro lugar, lembrar ao profissional que ele é um ser humano, e que o paciente também é. Algo evidente embora esquecido com muita frequiência. E a reflexão traz isto à tona com vigor. Se o cinema nos ajuda a pensar e a refletir sobre as coisas essenciais da vida, converte-se em recurso educacional de valor para formar pessoas. Aqui está a resposta à pergunta que costuma inaugurar os vários cenários educacionais aos quais sou convocado.

\section{Humanizando a saúde: quem, como, qual é o custo?}

Quem? A Humanização da Medicina assume notável protagonismo na agenda dos Educadores na Academia, e dos Gestores nos diversos Sistemas de Saúde. O motivo é claro: nos dias de hoje a medicina tem de ser forçosamente humana se quer pautar-se pela qualidade 
e pela excelência. Humanizar a Medicina é, assim, além de uma obrigação educacional, condição de sucesso para o profissional de saúde.

O clamor pela Humanização de uma situação, de uma atitude ou profissão é na verdade reclamar algo que se entende como essencial em determinada circunstância concreta. No caso que nos ocupa, as chamadas de atenção costumam vir da parte do paciente, como advertência que orienta na recuperação de algo que, tendo-se o direito de esperar do médico e da medicina, não se encontra na prática. As advertências provenientes do paciente dificilmente recaem no aspecto técnico, até porque o paciente não possui habitualmente recursos para avaliar corretamente deficiências dessa ordem. As carências que o paciente constata são, em última análise, carências na pessoa do profissional, detentor do conhecimento e intermediário entre a tecnologia e o paciente. As insuficiências não são de ordem técnica, mas humana. Torna-se necessário vestir a ciência médica com trajes humanos, dissolver no aconchego afetuoso a técnica moderna e os medicamentos que o paciente deverá utilizar. Quando tal não acontece, as insuficiências são sempre do profissional, e o prejuízo é do paciente, que acaba sofrendo de indigestões científicas nada reconfortantes. Caberá ao médico preocupar-se com esta temática, que não é minúcia ou filigrana. Uma preocupação que se deve traduzir em ocupação ativa; estudo, reflexão, para aprofundar e, sobretudo, analisar o seu comportamento, detectar as deficiências e encontrar os caminhos do necessário aperfeiçoamento.

Busca-se a humanização no sistema e nos processos, medem-se parâmetros de eficiência, certifica-se qualidade, mas percebe-se que falta algo. Humanizamos colocando quadros nas paredes dos hospitais, melhorando a hotelaria, sintonizando música ambiente, e até vestimos os funcionários com uniformes que incluem um sorriso plástico de vendedor, mas o cliente não está satisfeito. O cliente é o paciente que sofre, o aluno que não se sente compreendido, a família que está em desamparo. Gastam-se recursos abundantes nestas tentativas, mas parece que a humanização desejada não se atinge. Por quê?

O que está faltando é, por dizê-lo com palavras do romance de Graham Greene, o fator humano. As tentativas humanizantes debruçam-se sobre os sistemas e processos, mas não envolvem as pessoas que são a interface de humanização entre a medicina e o paciente. E não as envolvem, porque não sabem como fazê-lo. Os processos podem ser medidos e qualificados, mas o interior das pessoas -a boa vontade, a dedicação e carinho- são qualidades que fogem a qualquer auditoria de qualidade. Não é possível humanizar a saúde sem humanizar o profissional, sem que o humanismo penetre capilarmente na ação médica 
permitindo ao profissional harmonizar a técnica com o humanismo numa simbiose produtiva. (BLASCO; JANAUDIS; LEVITES, 2006).

O primeiro passo que o profissional deve dar se quer humanizar a saúde é admitir que, antes de tudo, se deve humanizar ele próprio. A responsabilidade primeira é toda dele, que deverá refletir e buscar recursos para integrar a técnica -atualizada e moderna- com o humanismo que a prática médica requer. E terá de instalar um processo de construção própria que lhe permita não esquecer o que de verdade importa. Porque, dito de modo simples, a desumanização da medicina é, sobretudo, um esquecimento lamentável daquilo que, sendo matéria de trabalho diária - o ser humano-, deixamos passar sem reparar na sua espessura, sem ponderar a dignidade que se envolve nesse relacionamento. Humanizar a Medicina será, de algum modo, recordar, um exercício ativo da memória para lembrar quem somos como médicos, o que buscamos, qual é a nossa história.

As tentativas de humanização de sistemas e processos - uma humanização ambiental, ecológica nos atreveríamos a dizer- são inúteis, desgastam o conceito de humanização, e fazem suspeitar que os desejos humanizadores não sejam sinceros. A vontade determinada de humanizar a saúde tem que priorizar os atores, os seres humanos, e não apenas o palco e a decoração. Projetos de humanização que não atinjam o âmago do ser humano -do médico, do profissional de saúde- transformando-o, são projetos abocados ao fracasso.

Como? A falta de uma metodologia para humanizar com eficiência é outro dos passos no itinerário do esquecimento. Não seria aventurado afirmar que os fracassos das tentativas humanizantes na medicina não se explicam apenas por falta de vontade política ou porque os desejos de melhorar não são sinceros. É possível que, mesmo imbuídos da melhor boa vontade, se careça de metodologia adequada. Para humanizar não basta querer: é preciso saber fazê-lo.

O humanismo em medicina não é uma questão temperamental, um gosto individual, ou até um complemento interessante. É uma verdadeira ferramenta de trabalho, não um apêndice cultural. Facilmente se compreende que sendo o próprio ser humano a matériaprima da ação em saúde, tudo aquilo que ajuda a entendê-lo melhor converte-se em instrumento profissional. Humanismo deve ser, pois, uma atitude científica, ponderada, resultado de um esforço de aprendizado.

Não é suficiente querer ser humanista, mas é preciso aprender a sê-lo. Seria uma imprudência deixar os desejos humanizantes por conta apenas da boa vontade. Nesse caso, tudo estaria em função da espontaneidade -mal chamada de carisma- sujeita à fragilidade dos 
altos e baixos da vida, em espectro que compreende desde a intuição oportuna -que pode vir ou não no momento preciso- até o trivial dos estados de ânimo, ou do desgaste da condição humana, que nem sempre apresenta a boa disposição que seria de desejar. A espontaneidade débil, desprovida de sustentação metodológica, é incompetente para educar, para formar pessoas; quando muito, estimulará um ou outro sonho que se desvanecerá ao contato com o prosaico do cotidiano. E os sonhos desfeitos -fogo de palha- rendem a cinza do sombrio ceticismo que contempla, lamentando-se, a ineficácia do seu empenho repleto de bons desejos, mas órfão de metodologia.

O Humanismo surge como uma fonte a mais de conhecimentos para o médico, como uma ferramenta de trabalho imprescindível, que é tão importante -não mais nem menos- como os muitos outros conhecimentos e habilidades que adquire na escola médica. O humanismo, para o médico, consiste essencialmente em adotar uma postura reflexiva no seu atuar, adotar um verdadeiro exercício filosófico da profissão, independente de qual seja o seu foco particular de atuação como médico (DECOURT, 2000).

No âmbito da educação em saúde, é fácil perceber a impossibilidade de ensinar a viver - no caso, ensinar uma atuação voltada para a compreensão da pessoa-, quando se carece de uma metodologia própria, quando não se percorreram pessoalmente os caminhos que levam a aprender a compreensão. Daí a responsabilidade que a formação universitária tem para fomentar a cultura que é, em definitivo, saber adotar um modo de posicionar-se no mundo, e perante os semelhantes (ORTEGA Y GASSET, 1999). Se a Universidade se preocupa apenas de treinar, ou capacitar profissionais, e descuida a promoção da cultura, é natural que o profissional esqueça os caminhos da compreensão, o gosto pela reflexão, o exercício filosófico que leva consigo a sua atuação prática.

Essa era a função das assim chamadas artes liberais, base da original educação universitária. O qualificativo de liberais implicava que não estavam diretamente destinadas a um aprendizado técnico específico - treino ou capacitação. Denominavam-se liberais porque não eram servis, já que não serviam para algo peculiar; sua utilidade consistia em construir o homem, o intelectual, e ajuda-lo a situar-se no mundo (NEWMAN, 1996)

Para ilustrar esta necessidade de metodologia não consigo evitar um exemplo cinematográfico. Trata-se de uma cena de Trezentos (300 - 2006), produção que certamente não conto entre as minhas preferidas, uma mistura de filme histórico e concurso televisivo de luta livre, maquiada de comics. Mas a cena é impactante. Leónidas, rei de Esparta, parte com seus 300 homens para enfrentar os persas de Xerxes na famosa batalha das Termópilas. No 
caminho, encontra um exército que pretende somar-se na empreitada, visto que esse pequeno número de 300 é desprezível perante os milhares de soldados persas. Leónidas recusa a ajuda, porque não quer amadores lutando do seu lado. "Qual é a tua profissão?" - pergunta o espartano a um soldado do exército de voluntários. "Ceramista, senhor" -responde o interpelado. "E você?" - continua perguntando Leónidas. "Eu sou ferreiro". A pergunta se sucede, e nova resposta: "Sou escultor". Volta-se para os seus homens e pergunta: "Espartanos, qual é a vossa profissão?" Um grito estarrecedor das 300 gargantas dissipa qualquer dúvida da competência bélica dos espartanos. Leónidas sorri e olhando o comandante dos voluntários afirma: "Parece que eu trouxe mais soldados do que você". Há uma diferença enorme entre a boa vontade, e o profissionalismo.

Qual é o custo? Eis uma terceira pergunta nas reflexões que nos ocupam de capital importância. Os projetos de humanização -aqueles que têm consistência, atingem o núcleo da pessoa, apoiam-se num método sistemático- não saem muitas vezes do papel, porque não são financiados adequadamente. Isto pode obedecer a dois motivos: um deles, ingênuo, pensando que humanizar implica uma atitude (o que é absolutamente correto) e as atitudes as pessoas as carregam consigo porque provavelmente as mamaram na infância e na sua educação familiar, e que seria algo que tem de se dar por suposto. O engano aqui é tremendo, porque as pessoas não incorporam as atitudes de por vida: podem, perfeitamente, abandoná-las em situações de cansaço, ou com as decepções que o dia a dia lhes traz. Por exemplo, a falta de agradecimento e a ausência de retorno diante da sua dedicação. A indiferença perante o esforço de alguém provoca uma terrível erosão das atitudes.

O segundo motivo, que é o mais grave, deve-se mesmo a uma falta de vontade política dos gestores, que não abrem espaço no orçamento nem na agenda para os projetos de humanização. Evidentemente, nunca se apresenta uma oposição aberta às iniciativas humanizantes, mas não são contempladas no setor financeiro. Com imensa frequência, comprovamos como congressos e fóruns de saúde, manejam polpudos orçamentos no referente à tecnologia -que é sempre o grande negócio- e deixam os temas que fomentam a humanização por conta de alguns idealistas que trabalham, na maior parte das vezes, gratuitamente. A injustiça é enorme, porque o chamado do evento costuma incluir o termo 'humanização', visto que tem apelo; mas na hora de fazer as contas, o Oscar de protagonista vai sempre para a tecnologia.

Humanizar a saúde tem o seu custo, e este vai acoplado às pessoas que tem competência em gerenciar o projeto, não apenas ao visual de hotelaria como equivocadamente 
se quer pensar, nem mesmo aos sistemas de tecnologia de informação. Querer fugir disso é insensatez e gestão deficiente, como seria contratar um regente de orquestra barato, porque já se gastou demais com os instrumentos e com o teatro; ou um técnico de futebol medíocre, porque o salário dos jogadores consumiu o orçamento. As consequências desse corte de despesas são fáceis de adivinhar.

\section{Educando as emoções: uma dimensão pedagógica esquecida}

O universo da afetividade - sentimentos, emoções e paixões - vêm assumindo um crescente papel de protagonista no mundo da educação. As emoções do aluno não podem ser ignoradas neste processo. Cabe ao educador contemplá-las e utilizá-las como verdadeira porta de entrada para compreender o universo do estudante. Formar o ser humano requer educar sua afetividade, trabalhar com as emoções. Como fazer isto de modo ágil, moderno, compreensível, eficaz? O Cinema mostra-se particularmente útil na educação afetiva, por sintonizar com o universo do estudante onde impera uma cultura da emoção e da imagem. Educar as atitudes supõe mais do que oferecer conceitos teóricos ou simples treinos; implica promover a reflexão que facilita a descoberta de si mesmo, e permite extrair do núcleo íntimo do ser humano um compromisso por melhorar (BLASCO, 2002).

É justamente no âmbito afetivo onde o personalismo se impõe como condição eficaz de aprendizado e assimilação de atitudes. Explicamos. Não deve haver muita diferença em expor os conceitos da física quântica, da astronomia, ou da fisiopatologia do câncer gástrico de modo objetivo ou levando em conta os sentimentos, que dificilmente modificarão as informações científicas. Mas quando se trata de promover atitudes, tomar decisões, provocar a reflexão, estimular a conduta ética, construir, enfim, a personalidade, não é em absoluto equivalente enunciar os princípios do bem agir -a modo de manual de boas maneiras- ou levar em consideração "o sabor desses princípios" e tentar torna-los palatáveis (BLASCO, 2006).

Aqui pode se encontrar o fracasso de tantas tentativas de "ética por atacado", "cursos intensivos de final de semana", ou mesmo a pouca eficácia dos códigos de ética de muitas profissões: falta-lhes "sabor", e sobram-lhes conceitos e regras que, por outro lado, são amplamente conhecidas. Se não se praticam não é por desconhecimento, mas por falta de motivação. Os sentimentos são, pois, como o tempero que facilita a ingestão do alimento, conferindo um toque especial de personalíssimo que faz do comer -por seguir a metáforaalgo que vai muito além da simples nutrição. E os temperos - que implica elaboração de 
molhos, condimentos e muita arte- devem ser preparados com alma de artista. A educação da afetividade requer arte de quem educa, criatividade para adaptar-se às necessidades de cada um, ao gosto de cada paladar -como fazem as mães e, nem dizer, ás avós- e que conquista a vontade, a nutre, e estimula para que cada um de o melhor de si. A afetividade modula o conhecimento dando-lhe um toque pessoal, como um prisma que amplifica, focaliza, dá zoom, destaca ou mesmo deforma a rigorosa objetividade dos conceitos e das ideias. Deve-se esperar de quem pretende educar as emoções que entre em sintonia com todo esse mundo subjetivo, que é afinal criação e arte.

A educação com o cinema arranca desejos profundos do jovem, motiva-o para grandes sonhos, para novos desafios. Lembro uma ocasião, num congresso de universitários, quando projetávamos a cena da batalha em $\boldsymbol{O}$ Último Samurai (THE LAST SAMURAI - 2003). Aqueles homens medievais, valentes, enfrentam as modernas metralhadoras, com a coragem $\mathrm{e}$ a espada. Mas a atitude de serviço - parece que esse é o motivo de ser dos Samurais, servir- e de chegar até o fim, arranca do inimigo o reconhecimento, a veneração e até a vitória moral. Esse é o modo de promover novos Samurais, mesmo com tecnologia moderna, de entre os jovens soldados que ficam atônitos vendo a valentia daqueles no combate. Quando acabou a conferência e os comentários das cenas, antes de sair, um aluno veio até a frente, me segurou pelo braço e me disse com os olhos brilhando: "Professor, eu quero ser um Samurai!!!".

O cinema é também um modo de se entender, de exprimir o aquilo que a racionalidade levaria muito tempo para explicitar, e acabaria resultando até enfadonho. Vale reproduzir o comentário de uma conhecida nossa, professora e mãe de família numerosa, a respeito de King Kong (KING KONG - 2005). "Esse é o homem que toda mulher gostaria de ter do lado! " "Mas como um homem? -exclamo eu- estamos falando de um gorila". E ela continua sorrindo; "Engano seu, meu caro; ele luta por ela, a defende, se bate, se deixa ferir...e aprende dela a delicadeza, os modos, a poesia. E quer somente ela. As outras mulheres que lhe apresentam ele as descarta. " Surpreso pelo comentário, lembrei-me do pensamento de Ortega (ORTEGA Y GASSET, 1980) que diz: "Nada imuniza tanto um homem do universo das mulheres, como a amor apaixonado por uma delas. " E, em outra ocasião, quando o filósofo comenta "A mulher muda o ambiente e o homem, como o clima trabalha os vegetais, sem fazer aparentemente nada, formando-o à sua imagem e semelhança”.

\section{O Cinema, um promotor de reflexão}


Vale esclarecer que a educação através da estética, que atinge as emoções e a sensibilidade não é uma tentativa de apoiar na emotividade a educação do jovem. Trata-se de suscitar uma reflexão sobre os valores e atitudes. É possível incorporar um conhecimento técnico ou mesmo treinar uma habilidade sem refletir sobre eles; mas é impossível adquirir valores, progredir em virtudes, incorporar atitudes, sem um prévio processo de reflexão. É justamente desencadear este processo de reflexão, mediante recursos próximos ao estudante, o que o se pretende com a estética, da qual o aprendizado através do cinema faz parte (BLASCO, MORETO, RONCOLETTA LEVITES, JANAUDIS, 2006). Dito de outro modo: estabelecer um ponto de partida para uma atitude reflexiva, pista de decolagem para futuros aprendizados, sensibilização para ensinamentos posteriores que virão através de conteúdos específicos e, na maior parte das vezes, personalizadas em exemplo.

Este processo requer tato, habilidade, evitar precipitações, promovendo um aprendizado que respeite, de alguma maneira, o ritmo quase fisiológico da emotividade. Não se pode obrigar a ninguém a sentir o que não sente. Pode-se simplesmente mostrar, e o tempo -e a reflexão sobre as emoções- se encarregarão de aprimorar o paladar afetivo. Um processo que foi denominado, com sabor clássico, “educação sentimental". Esta seria a função do educador, afinal um promotor da cultura que deve despertar o desejo por aprender, contagiar o entusiasmo por conhecer e conseguir que o estudante invista o melhor dos seus impulsos para procurar, também por meios próprios, o conhecimento que lhe será de utilidade.

Este poder de estimular a reflexão torna-se sobremaneira evidente com a figura do clássico O Rei Leão (THE LION KING - 1994). Simba está na boa vida, e não quer assumir que cresceu. O macaco lhe interroga e lhe pergunta "Quem é você?" E esta pergunta vira do avesso o confortável Hakuna Matata em que Simba vivia para trazê-lo à realidade. A seguir, o macaco lhe mostra o caminho para encontrar o seu pai. Simba tem dificuldade porque não está acostumado a refletir e, no início, apenas vê a própria imagem refletida na água. "Olhe com mais atenção, Pense. Reflita". E chega o grande susto: "Simba, você me esqueceu. Sim, você me esqueceu, porque esqueceu quem você é. Você não é um gatinho, mas o meu filho, o verdadeiro Rei Leão". O que de melhor se pode fazer é promover a reflexão, para que o jovem se vá construindo. Algo muito próximo ao que o macaco Rafiki faz com Simba. Não são as respostas as que devem vir prontas, fabricadas, mas sim as perguntas a modo de provocações que o professor deve continua e serenamente dirigir ao se interlocutor. A ficha tem de cair por si só - por utilizar uma linguagem moderna. E, nesta empreitada de provocar reflexões, o Cinema é um prato cheio, uma oportunidade excelente. 
O cinema faz refletir, as cenas são verdadeiros questionadores. Lembremos de $\boldsymbol{O}$ Resgate do Soldado Ryan (SAVING PRIVATE RYAN - 1998). Tom Hanks, o capitão, está morrendo. O soldado Ryan inclina-se sobre ele. E o capitão apenas lhe diz; "James, faça por merecer". 40 anos depois, James Ryan comparece ao cemitério acompanhado da sua família: mulher, filhos e netos. Esse é o seu curriculum vitae, o que ele andou fazendo nestes anos. E vem prestar contas: "Todos os dias penso no que você me disse aquele dia na ponte. Procurei viver a minha vida do melhor modo possível. Espero que pelo menos diante dos teus olhos eu tenha feito por merecer aquilo que todos vocês fizeram por mim”. E, não satisfeito, procura a avaliação doméstica da sua vida, de que a sua vida prestou, foi útil, e convoca a sua mulher e lhe diz; "Diga que sou um homem bom, que tive uma vida digna". O capitão - que era na vida civil um professor- educou James Ryan com essa simples frase - "faz por merecer"- e com o seu exemplo de vida. Para qualquer um que medite nesse contexto, baste lembrar-lhe que faça por merecer, para que tudo venha à tona na cabeça e no coração.

Mas tudo isto não será muito perigoso? Não levantará problemas com os quais não saberemos depois lidar? Vem à minha memória um fato acontecido num Congresso Internacional em Florença há mais de dez anos. Foi durante um workshop onde apresentamos a metodologia reflexiva que o cinema oferece ao educador (BLASCO, 2013). Curiosamente a platéia -mais de 100 pessoas- estava composta integralmente por outros que não latinos: finlandeses, ingleses, alemães, dinamarqueses, noruegueses, belgas, holandeses. Diante desse público, novidade para mim, tive um momento de hesitação. Funcionaria com eles como tinha funcionado no Brasil e em ambientes latinos? Projetar trechos de filmes, fazer comentários simultâneos? Uma audiência onde, possivelmente, a manifestação dos sentimentos teria uma linguagem de expressão diferente? A sessão correu bem, em silêncio profundo, e deixavam-se ouvir -mesmo sem a estrondosa componente latina- alguns suspiros emocionados. No final, um professor britânico pediu a palavra:

- "Isto que vocês fazem e muito perigoso!!!"

- ????

- "Sim. Este despertar emoções nos jovens pode trazer à tona graves problemas que estão lá enrustidos".

Enquanto me preparava para responder com a maior delicadeza possível, um finlandês levantou a mão e respondeu: 
- Meu caro amigo. Os problemas estão lá e virão à tona, conosco, sem nós ou apesar de nós. Isto funcionará perfeitamente no meu pais, e na minha universidade.

Faltou tempo para que um outro assistente, um professor da Noruega com feições de Viking, comentasse de modo contundente:

- "Penso que somente pode ter medo de fazer algo assim quem tem medo das próprias emoções".

Não houve necessidade de nenhum esclarecimento da nossa parte. E, confortavelmente, a sessão prolongou-se por mais meia hora, entre comentários e sugestões com sotaque britânico, eslavo e germânico.

\section{Humanização Sustentável: Promover o habito da reflexão}

A humanização da saúde começa pelo desejo sincero e real que o profissional deve ter de humanizar-se ele próprio. O conhecimento próprio é o ponto de partida. A reflexão honesta sobre quem somos e os objetivos que nos propomos, é condição imprescindível para reconstruir-se na dimensão humanista. Bem o advertiam os antigos, quando destacavam como início da sabedoria o "conhece-te a ti mesmo".

Um ensaio elegante de anos atrás coloca a questão com acerto. (BOGDEWIC, 2000). Relata-se a história de certo filósofo inglês que tinha uma curiosa gravação que atendia os chamados telefônicos quando ausente. A secretária eletrônica - answering machine, em inglês, textualmente “máquina de responder"- dizia: "Isto não é uma máquina de responder; é uma máquina de fazer perguntas -questioning machine. Quem é você e o que quer da vida?" Diante da surpresa, o perplexo interlocutor ouvia alguns segundos depois prosseguir a gravação: "Não se assuste. A maioria das pessoas vêm a este mundo e vão embora, sem ter respondido estas duas simples questões". Saber quem somos e o que queremos é condição sine qua non para atuar de modo consciente e responsável.

Certamente não se chega a estas profundidades reflexivas na prática médica diária, e talvez o problema se encontre aí; e o dilema persiste enquanto se buscam soluções teóricas desatendendo o centro real da questão. E por esse mesmo motivo a fácil tentação do conhecimento crescente - a confortável sedução da informação científica- nos distrai daquilo que deveria ser a principal ocupação: o crescimento pessoal. Bem o adverte outro pensador quando afirma: "Não é difícil entender porque gostamos tanto de aumentar nosso 
conhecimento e tão pouco de aumentar a capacidade de amar. O conhecimento traduz-se automaticamente em poder, enquanto o amor se traduz em serviço" (CANTALAMESSA, 1998).

O amor pela tarefa que temos entre as mãos é fonte de sabedoria, e abertura para um humanismo cheio de competência. As sabias palavras de Gregório Marañón -paradigma de médico humanista- lembrando os antigos médicos familiares, ilustram este ponto de modo comovente: "Eles tinham um sentido da Medicina mais cordial, mais humano. Permanecia neles a figura do velho médico familiar, conselheiro, sacerdote, amigo nos momentos difíceis em cada lar. É provável que não soubessem tanto como nós, mas certamente foram melhores e mais sábios. Infelizmente, vamos esquecendo que a sabedoria não é somente saber as coisas, mas também amá-las" (MARAÑÓN, 1967).

A reflexão que nos ocupa é de caráter fenomenológico e vital. Não é possível medir quantitativamente, pois diz respeito à atitude do profissional, ao interesse. Talvez a cristalização deste interesse -a imagem é também de Marañón- seja a cadeira, que ele considerava o elemento humanizante por excelência na prática médica. Quando o médico se senta para conversar com o paciente está lhe indicando com a sua atitude que tem todo o tempo do mundo para escutá-lo. Hoje temos computadores, prontuários eletrônicos, técnicas sofisticadas, mas talvez nos faltem cadeiras; ou, pior, perdemos o gosto por sentar-nos nelas, do lado do paciente. A boa medicina à beira do leito tinha este componente humanístico da proximidade física com o paciente, do tempo gasto em companhia dele.

Outra cena cinematográfica acode à minha mente. Trata-se do filme de Hannah Arendt (HANNAH ARENDT - 2012) e a explicação acadêmica na Universidade sobre a reportagem realizada para The New Yorker, que depois converteu-se em livro (ARENDT, 1963) era contundente. Cinco minutos de filme, definitivos. "Quando vi Eichmann não me pareceu ser o demônio, ou um criminal sádico. Insistiu, uma vez e outra, que nunca tinha feito nada por iniciativa própria, que somente tinha cumprido ordens. O maior mal no mundo é cometido por pessoas comuns, não por diabos ou monstros; são pessoas que simplesmente deixam de pensar, de refletir. Este fenômeno é o que eu denomino a banalidade do mal. O que encontrei nesse homem foi a chocante mediocridade de um homem que abriu mão da maior das qualidades humanas: a capacidade de pensar. Esta atitude de irreflexão é o que permite que gente comum acabe cometendo as maiores barbaridades e crimes"

Desvenda-se assim o processo através do qual as pessoas -os médicos incluídosabdicam da própria responsabilidade. Não maltratamos os pacientes porque somos malvados 
ou porque não nos preocupamos com eles. Simplesmente temos tanto que fazer, estamos tão ocupados buscando as melhores evidências e possibilidades de abordagem científica, os melhores tratamentos, que nos distraímos. E nessa distração descuidamos os detalhes, nos omitimos na percepção empática, esquecemos o protagonista do cenário: o paciente. Seguimos os protocolos e os guidelines, nos certificamos de escolher sempre o melhor. Sem dúvida obedecemos também às ordens que o comando científico nos recomenda. E nesse empenho, que por vezes raia o burocrático, nem sempre damos ouvidos ao que o paciente tem a nos dizer. Como se as vezes esquecêssemos que tratamos com seres humanos.

As maiores tragédias procedem não dos demônios, mas de gente normal que simplesmente parou de pensar. É o sistema de saúde no qual estamos envolvidos que funciona como desculpa para deixar de refletir, para abrir mão da responsabilidade pessoal. É fazer o que todos fazem, o que sempre se fez; deixar como está para ver como é que fica. E quando as catástrofes acontecem -os erros, as queixas dos pacientes maltratados, os descasos corriqueiros- nos escandalizamos e qualificamos o colega que protagonizou o evento como um monstro. Lembro de ter comentado sobre esta vivência com uma professora de humanidades, também admiradora de Hannah Arendt, que leciona numa Universidade americana. Sorriu e me disse: “É muito confortável qualificar alguém como um monstro. É como se pertencesse a uma classe de seres diferentes de nós mesmos, e nós estamos a salvo. Mas, ao contrário, quando reconhecemos que a maldade procede de seres comuns que deixam de pensar, reparamos que a qualquer momento podemos ser nós mesmos os protagonistas dessa triste ação. Basta deixar de refletir no que estamos fazendo".

\section{A Formação Humanista: Um desafio permanente}

Ensinar humanismo é fomentar a reflexão sobre a condição humana, situação que envolve não apenas o paciente, como os próprios interessados: alunos e professores. Não é um processo inócuo, onde quem o estuda se situa em posição isenta. Legisla-se em causa própria, e as conclusões comprometem, em primeiro lugar, o próprio legislador - o estudioso-, que não tem como furtar-se às consequências das suas próprias reflexões. E assim, o que muitas vezes começou como pouco mais que uma curiosidade cultural, ou como necessidade instrumental da profissão que se quer exercer, debruça-se sobre a própria vida, envolvendo-a e interferindo sobre os próprios valores e perspectivas. A competência que buscamos na formação dos futuros médicos implica Humanismo. Sem Humanismo, não há competência possível. 
Formar médicos humanistas vai muito além de dar um verniz humanitário ao futuro medico, mas instalar um processo de reflexão que lhe permita, de modo continuado, reavaliar sua opção vocacional, sua resposta como pessoa e como profissional. Um elemento essencial que se insere na alma do profissional e se faz vida da sua vida. (LEVITES, BLASCO, 2009)

O tema do humanismo médico -ou da humanização da medicina- não é algo novo, mas preocupação sempre presente nos acadêmicos que comentam acerca do equilíbrio que sempre se deu na medicina, entre as duas facetas que a compõem: a medicina como ciência, e a medicina como arte. (ROBB, 1985) Os vertiginosos avanços científicos requereriam, para manter esse equilíbrio, uma ampliação do âmbito do humanismo, quer dizer, um humanismo que fosse proporcional ao progresso técnico. Quando essa atualização moderna do humanismo não acontece, os resultados são profissionais formados tecnicamente, mas com sérias deficiências humanas. Profissionais disformes, com hipertrofias científicas e atrofias humanísticas, que não são capazes de inspirar confiança ao paciente. Como resolver este dilema? Ou melhor: Como resolvê-lo de modo sustentável e instalar um processo sólido de volta ao Humanismo Médico? Afinal, como formar este profissional do qual precisamos? Na verdade, a questão é vital, porque se trata de resgatar a essência do ser médico. Humanizar o médico é no fundo um contrassenso. $\mathrm{O}$ humanismo é inato à profissão médica. Um médico sem humanismo não será propriamente médico. Na melhor das hipóteses trabalhara como um mecânico de pessoas (BLASCO, 1997).

Toda a responsabilidade recai, assim, no processo de formação do profissional E aqui o desafio é enorme, porque não se trata de importar conceitos humanistas de outrora, num saudosismo estéril, abominando do progresso. Não se pode ser médico humanista, com um humanismo do século passado. Requer-se a construção de um novo humanismo médico que integre todas as dimensões da atuação médica em unidade harmônica, em sólida competência.

O pensador francês Gustave Thibon (THIBON G, 2005) reúne um conjunto de ensaios num volume que intitula "O Equilíbrio e a Harmonia". O equilíbrio é composição de forças contrárias, solução de compromisso, resultante de vetores que se anulam entre si. A harmonia é o encaixe perfeito das partes de um todo, em colaboração perfeita para uma mesma finalidade. E, citando Vitor Hugo, comenta: 'Por cima do equilíbrio encontra-se a harmonia, por cima da balança encontra-se a harpa'.

É bem possível que as tentativas humanizantes na saúde incidam neste erro: uma busca do equilíbrio, ao invés de promover a harmonia. $\mathrm{O}$ equilíbrio da por suposto que a ciência moderna apoiada em evidências tem de ser temperada com atitudes humanistas, ou 
humanitárias. Assim escutar com carinho a história do paciente, sentir compaixão, e posturas análogas. Mesmo reconhecendo nesses modos um notável avanço sobre o descaso que diariamente contemplamos para com o paciente e a família, pode se entrever um equilíbrio frágil, de pouca consistência. Na prática continuaremos admitindo duas posturas que não se misturam, como o azeite e a água. Agua clara das evidências, e o azeite que conforte. Mas cada um com densidade própria, aplicados no seu tempo e no momento pertinente. Esta "esquizofrenia da atuação médica" é insustentável em si mesma, dura pouco, e quando o médico se canse prestará atenção a um aspecto em detrimento do outro.

A ciência médica, a medicina de ponta, exige hoje um novo humanismo. É necessário instalar uma postura que saiba colocar no mesmo raciocino a função hepática e as sequelas neurológicas, com o sentido da vida; as transaminases e a albumina combinadas com a humilhação, o sofrimento e a perda. Uma ciência que é arte e por isso consegue situar na mesma equação dimensões tão dispares, que aparentemente não se misturam. Na verdade, estão misturadas completamente na própria vida: a protrombina e o desânimo, os neurotransmissores e o cansaço de viver, os hepatócitos e a indignação (BLASCO, 2006).

Este novo humanismo médico deve construir-se pautado pela harmonia, para saber tocar, com diferentes cordas, o acorde perfeito. Equilíbrio é optar por uma composição unitônica, ora ciência, ora arte; um pouco de albumina, e medidas doses de afeto. Harmonia é colocar cada competência no seu lugar, ter alma de artista para saber tocar a harpa dos cuidados médicos, incorporar a polifonia com variedade de instrumentos, com silêncios e compassos de espera, na sinfonia de cada vida humana que nos é confiada. Estes são os acordes que permitem ao médico percorrer o caminho entre a pessoa doente e o significado que a doença tem para o paciente, já que a enfermidade é para o paciente um modo de estar na vida. Uma forma de vida que tem sua própria linguagem e deve encontrar no médico sensível, o receptor necessário para decodificar corretamente os significados. O novo humanismo médico é verdadeira antropologia ativa, e não simples especulação teórica. "Para o profissional da medicina, humanismo e antropologia são possibilidades da sua auto exigência, desafios ao seu pensamento racional, níveis de conhecimento em aspiração ascendente de inconformismo" (MONASTERIO, 1982).

O humanismo médico é fonte de conhecimento que o médico utiliza para melhor cuidar do ser humano que lhe é confiado. Caminhos diversos de conhecimento que encontram na pessoa do paciente o terreno comum de atuação, a unidade de missão. Um humanismo que vai além do equilíbrio que pretende compensar os excessos da técnica colocando na balança 
esporádicas atitudes humanitárias. Um humanismo que representa a harmonia do verdadeiro virtuosismo musical e não apenas de um apêndice cultural. Uma atitude científica, ponderada, resultado de um esforço consciente de aprendizado possuidor de metodologia consistente (RONCOLETTA et al, 2003; BLASCO, BENEDETTO, REGINATO, 2015).

A proposta de um novo modelo de humanismo médico surge assim como uma possibilidade sustentável para humanizar a Medicina, porque moldaria o processo de formação do médico na mesma fonte acadêmica. E deste modo, poderia viabilizar-se esse modelo humanista que resulta da harmonia precisa que sabe combinar em perfeita sintonia a ciência de uma medicina moderna, baseada em evidências, com a arte e os cuidados que implica entender o enfermo como pessoa, centrar-se no paciente e não apenas na doença que lhe acomete (BLASCO; MORETO, 2012). Cabe aos educadores e gestores o compromisso de fazer do processo de humanização em saúde um caminho real, concreto e prático. $\mathrm{Na}$ construção deste caminho a educação com o Cinema (BLASCO, 2011) oferece uma metodologia simples, acessível e divertida para aperfeiçoar seu desempenho.

\section{Referências}

300 (2006). 117 min. Director:.Zack Snyder. Gerard Butler, Lena Headey, David Wenham. Cfr: http://www.imdb.com/title/tt0416449/

ARENDT, H: Eichmann in Jerusalem: A Report on the Banality of Evil(1963)

BLASCO et al. (Humanities Through Cinema: Using Movie Clips to Teach Family Medicine Core Values and address students emotions. 2006. Seminar. 12th Wonca Europe 2006 Meeting: Toward the Medical Renaissance. Bridging the gap between Biology and Humanities, Firenze, Italy) in BLASCO PG. Lições de Liderança no Cinema. SOBRAMFA Educação Médica \& Humanismo, São Paulo. 2013, v.1. p.299.

BLASCO PG, BENEDETTO MAC, GARCIA DSO, MORETO G, RONCOLETTA AFT, TROLL T. Cinema for educating global doctors: from emotions to reflection, approaching the complexity of the Human Being. Primary Care.2010. 10: 45 - 47.

BLASCO PG, BENEDETTO MAC, REGINATO V. Humanismo em Medicina. SOBRAMFA-Educação Médica e Humanismo. São Paulo. 2015. 
BLASCO PG, GONZÁLEZ-BLASCO M, LEVITES MR, MORETO G, TYSINGER JW. Educating through Movies: How Hollywood Fosters Reflection. Creative Education. v.2, p.174 - 180, 2011

BLASCO PG, JANAUDIS MA, LEVITES MR. Un nuevo humanismo médico: la armonía de los cuidados. Aten Primaria. 2006;38(4):225-9.

BLASCO PG, MORETO G, RONCOLETTA AFT, LEVITES MR, JANAUDIS MA. Using movie clips to foster learners' reflection: Improving Education in the Affective Domain. Fam Med 2006; 38(2) 94-6

BLASCO PG, MORETO G. I Feel Your Pain: Empathy in Medicine In: Cinemeducation: Using Film and Other Visual Media in Graduate and Medical Education.1 ed. London, UK : Radcliffe Publishing Ltd, 2012, v.II, p. 527-541.

BLASCO PG. Educação da Afetividade Através do Cinema. IEF- SOBRAMFA. São Paulo. 2006.

Educação Médica, Medicina de Família e Humanismo: expectativas, dilemas e motivações do estudante de medicina analisadas a partir de discussões sobre produções cinematográficas. Tese Doutoral. Faculdade de Medicina, USP. São Paulo, 2002. Cfr. http://www.teses.usp.br/teses/disponiveis/5/5144/tde-31082009-085309 . Humanizando a Medicina: Uma Metodologia com o Cinema. Centro Universitário São Camilo. São Paulo. 2011.

. O Médico de Família, hoje. Sobramfa. São Paulo. 1997

BOGDEWIC S. The Questioning Machine. Fam Med. 2000.32(10):670-2

CANTAlAMESSA, R. Il Canto dello Spirito. Ed Ancora. Milano. 1998.

DECOURT LV. William Osler na Intimidade de Seu Pensamento. Revista do Incor, 2000 HANNAH ARENDT (2012)113 min Director: Margarethe von Trotta. Barbara

Sukowa, Axel Milberg, Janet McTeer. Cfr: http://www.imdb.com/title/tt1674773/

KING KONG (2005). 187 min. Director: Peter Jackson. Naomi Watts, Jack Black, Adrien Brody. Cfr: http://www.imdb.com/title/tt0360717/

LEVITES MR, BLASCO PG. Competencia y Humanismo: La Medicina Familiar en Busca de la Excelencia. Archivos de Medicina Familiar y General. 2009. 6: 2 - 9 
MARAÑÓN G. Mi homenaje a Francisco Huertas. in Obras Completas, vol III Espasa Calpe. Madrid, 1967

MONASTERIO F. Planteamiento del Humanismo Médico. Humanismo y Medicina II Encuentro Cultural de la Sociedad Española de Médicos Escritores. 1982.

NEWMAN JH. Discursos sobre el fin y la naturaleza de la educación universitaria. Eunsa. Pamplona. 1996.

ORTEGA Y GASSET J. “Missão da Universidade” EdUERJ. Rio de Janeiro 1999

ORTEGA Y GASSET J. Estudios sobre el Amor. Revista de Occidente. Madrid. 1980

ROBB D. "Ciência, Humanismo e Medicina”. Rasegna, n.3, 21-32. 1985

RONCOLETTA AFT, MORETO G, LEVITES MR, JANAUDIS MA, BLASCO PG, LEOTO RF. Princípios da Medicina de Família. SOBRAMFA. São Paulo 2003.

SAVING PRIVATE RYAN (1998). 169 min. Director: Steven Spielberg. Tom Hanks, Matt Damon, Tom Sizemore. Cfr: http://www.imdb.com/title/tt0120815/

THE LAST SAMURAI (2003). 154 min. Director: Edward Zwick. Tom Cruise, Ken Watanabe, Billy Connolly. Cfr: // http://www.imdb.com/title/tt0325710/ THE LION KING (1994). 88 min. Cfr: http://www.imdb.com/title/tt0110357/ THIBON G. El Equilibrio y la Armonía. Belacqua. Barcelona 2005. 